\title{
Comparison the Effects of Communication and Conflict Resolution Skills Training on Marital Satisfaction
}

\author{
Mahin Askari (Corresponding author) \\ Educational of Studies, Univerisity Putra Malaysia \\ Serdang, Selangor 3400, Malaysia \\ $\&$ \\ Research Center for Social Determinants in Health Promotion \\ Hormozgan University of Medical Sciences \\ Bandar Abbas, Iran \\ E-mail: mahinask2005@yahoo.com \\ Sidek B. Mohd Noah \\ Educational of Studies, Univerisity Putra Malaysia \\ Serdang, Selangor 3400, Malaysia \\ Siti Aishah Bt Hassan \\ Educational of Studies, Univerisity Putra Malaysia \\ Serdang, Selangor 3400, Malaysia \\ Maznah Bt Baba \\ Educational of Studies, Univerisity Putra Malaysia \\ Serdang, Selangor 3400, Malaysia
}

Received: June 1, 2010

Accepted: January 13, 2012 Published: March 1, 2012

doi:10.5539/ijps.v4n1p182

URL: http://dx.doi.org/10.5539/ijps.v4n1p182

\begin{abstract}
The purpose of the study was to examine the effects of communication and conflict resolution skills training on marital satisfaction among Iranian couples based on PREPARE-ENRICH program. In this study, marital satisfaction was measured by ENRICH Marital Satisfaction. The methodology of this study was experimental method; with pre-test, post-test, and control group design. Purposive sampling was conducted to select the sample that was included 54 couples who were consisted of all couples referred to the researcher by counselling centres. The referrals were done for about two months in 2009. These couples were randomly assigned to an experimental and a control group as well. The dependent variables were marital satisfaction, and the independent variables were communication and conflict resolution skills training. Consequently, the results indicated that communication and conflict resolution skills training improved marital satisfaction $(p<.05)$. Moreover, the results showed that communication and conflict resolution training was effective in martial satisfaction in post-test $(\mathrm{p}<.05)$. In conclusion the findings of this study indicated that the on PREPARE-ENRICH program can be effective in improving marital satisfaction among Iranian couples.
\end{abstract}

Keywords: Communication, Conflict resolution skills, Marital satisfaction, Iran

\section{Introduction}

This study aims to investigate the effects of communication and conflict resolution skills training on marital satisfaction among couples who were facing marital conflicts. Nowadays, marriage instead of being pleasant 
enduring has become the most disappointing and fragile relationship to a great number of people (Olson \& Olson, 2000). Universally, marriage is a foundation in every society. It can be the most nourishing and enduring asset in human relationship as pointed out by Olson and Olson (2000). Larson and Holman (1994) posit that marriage provides the fundamental structure for establishing family relationships which are aimed at expanding the family by creating the next generation. A healthy marriage is characterized by a series of constructive influences and changes in the physical and emotional health of adults and children (Waite \& Gallagher, 2000). The decision to marry is a crucial decision in one's life. However, most people do not invest their time and energy before getting married in preparing themselves for their marital relationship. Some couples spend more time preparing for the marriage ceremony, instead of building skills for a sustainable marriage (Olson \& Olson, 2000).

The term marital satisfaction has proven to be rather elusive to define, often used interchangeably with the terms marital quality, and dyadic adjustment (Harper, Schaalje, \& Sandberg, 2000). Husband and wife's ability to accommodate each other at any given time is defined as marital quality. Moreover, it can depict a single dimension like communication or perhaps the successful general functioning of a marriage (Harper et al., 2000).

There is a high correlation between communication and conflict resolution skill of couples, and marital adjustment or divorce rates (Christensen \& Shenk, 1991). Most of the divorce cases are due to the unresolved marital conflicts among the couples (Samani, 2008, Zargar \& Doost, 2008, Schneewind, Klaus, \& Gerhard, 2002). An investigation by Zargar and Doost, (2008) and Khojastehmehr and Takrimi (2009) demonstrated some common factors related to divorce in Iran. They reported that lack of communication skills, conflict over roles/responsibilities, husband's physical and verbal abuse and lack of social skills as the major divorce factors. In their study Zargar and Doost (2008) point out communication problems as the most important divorce factor in Falavarjan, Iran. Consequently, there is an insufficient level of communication, which leads to family problems and contributes to stress levels of the couple. With a rise in the quantity of such problems and the level of marital stress, the couple's satisfaction levels fall (Christiansen \& Shenk, 1991).

Samani (2008) investigated the important factor of marital conflict between married students in Shiraz University of Iran. The result of this study revealed that there are six important factors of marital conflict which are personality traits, love and affection, communication skills, commitment, family background and refinement.

Even though there are large bodies of research on the effectiveness of marital education programs in western countries, there is a lack of experimental studies on the effectiveness of such programs in Iran. There has been no report of the impacts of such programs on health issues, as well. Hence, this study attempts to investigate the effect of a marriage enrichment program on Iranian couples, who are facing marital conflicts. Specifically, would communication and conflict resolution skills help couples to cope or overcome their marital conflicts and improve their marital satisfaction? To seek due answers to this question, the researcher through reviews, adopted a successful preventive program, based on the PREPARE/ENRICH. The PREPARE/ENRICH program is based on the empirical evidence over twenty years research developed by Olson and Olson (2000). The objectives of this study are to examine the difference in marital satisfaction between pre-test and post-test experimental group and also to examine the difference in marital satisfaction between post-test experimental group and control group.

\section{Literature Review}

The majority of researchers on marital communication are dedicated to the relationship between communication skills and marital satisfaction (Westerp, 2002). Both positive and negative communication interactions findings typically reveal that married couples, who display frequent negative interactions, are more likely to experience strained relationships (DiLillo, 2001; Bradbury, 1999). Other studies (Gottman \& Driver, 2004) focus on the interaction between couples, in the determination of marital outcome. These studies investigated the way partners communicate with one another, and of particular interest is their conflict resolution and affective communication skills (Greef \& De Bruyne, 2000). The way in which couples argue has been shown to be important, and the expression of affection they have for one another has proved to be significant in determining marital outcomes. Other interpersonal factors include couple's behavior towards one another. In short, communication has long been the research focus for marital researchers and many studies have found an association between communication and relationship satisfaction (Bradbury \& Karney, 1993; Christensen \& Shenk, 1991). It has been indicated that communication behaviors and interaction patterns are evidently related to marital satisfaction.

In 2008, Boostan, Hashemian, Shafiabadi and Delavar conducted a study on a comparative study of the effectiveness between group couple therapy using the teaching two approaches of family therapy namely, "the redecision therapy" and the narrative therapy on increasing marital satisfaction of married Iranian student. The 
purpose of the research was to investigate the effectiveness of two therapies and also the integration of these therapies with "positive psychology". So as to reach these goals the process of group counselling was used, in the study. The research design in the study was pre-test and post-test with control group. The total population of the research was all married students of Tehran University who were married for at least two years. From this population, just 20 couples were the respondents of this survey. Enrich marital satisfaction questionnaire was used as an instrument for the pre-test and post-test. After administering the pre-test, the samples were randomly chosen in 3 experimental groups and one control group. The experimental groups were under 5 sessions of 2 hours of group counselling. Then all of the four groups were given the same questionnaire. The dependent variable in the research was examined in 2 ways. Subscale of marital satisfaction and total index of marital satisfaction. The results were analyzed by descriptive and inferential statistic (independent t-test, ANOVA and Turkey's test). The findings indicated that the intervention had positive impacts on marital satisfaction of the Iranian couples who participated in the programme as experimental groups.

Respect among couples is closely related to the level of marital satisfaction. This was revealed in a study conducted in Qom City in Iran, which investigated the relationship between mutual interest and respect and the level of satisfaction with their marriage. There were firm indications that the more the spouses respected and loved each other, the happier was their marriage (Danessh \& Hydarian, 2006).

In a study, the researchers divided marital quality into three dimensions, namely, spouse's reports of happiness within the marriage, frequency of shared time together, which they call marital interaction, and thoughts or actions which may lead to divorce, which they called divorce proneness. Throughout a long-term marriage, the level of marital satisfaction does not remain constant (Amato, Johnson \& Rogers, 2003).

Other researchers performed a research on comparison between dual career couples and single career couples on marital satisfaction in Iran. The study aimed to compare marital satisfaction between dual career couples and single career couples in Iran. The subjects were randomly selected which comprised 50 dual career couples and single career samples among Iranian couples. The total number of 50 dual career couples and 50 single career couples were randomly selected. All the respondents completed the MSI-R.MSI-R test used to evaluate marital satisfaction. The test has 11 sub-scales. The findings revealed that that in marital satisfaction and the subscales of global distress, time togetherness, role orientation, dissatisfaction with children and conflict with children rearing of the two groups were significantly better than single career (Nazari \& Soleimanian, 2008).

Additionally, Nazari and Navabinezhad (2007) conducted a study to examine the effect of solution-focused counselling on marital satisfaction of dual-career Iranian couples. Twenty four couples participated in the research. At the beginning, all of the couples were given "MSI-R" (Marital Satisfaction Inventory) as pre-test. Based on the result of the pre-test the couples were randomly divided into three groups; Twelve couples assigned into the control group and the rest in solution-focused group. Seven sessions of solution-focused counselling was conducted for the experimental group while control group was in waiting list. At the end of the experiment, these two groups received "MSI-R" as post test and follow-up test (after one month). The findings of the research demonstrated that solution-focused counselling increased the marital satisfaction of the Iranian couples significantly.

\section{Methodology}

\subsection{Research Design}

The research design used in this study was pre-test and post-test research design, which includes control and treatmental groups. Pretest-posttest designs are research designs widely used in behavioral research, for comparing groups and measuring change resulting from experimental treatments (Dimitrov \& Rumrill, 2003). It is a classic design that involves the random assignment of subjects to two or more groups. The treatment is applied only on the treatment group.

In this design, subjects are assigned to treatment and control groups through randomization. Treatment is introduced to the experimental subjects for a specified time, after which the two groups were measured based on the dependent variable. The purpose of the control group is to enhance the comparison with the treatment group (Ary et al., 2002). In the present study, pre-test and post-test are carried out to determine the effects of communication and conflict resolution skills training on marital satisfaction in the treatment group when compared with the control group.

\subsection{Internal and External Validity}

A study with an experimental design needs to take into account the possible threats that may confound the effects of instruction. This section concerns the possible internal and external validity threats related to the current study. 
Based on Ary et al (2002); Campbell and Stanley (1996), internal validity is the extent to which the changes observed in an dependent variable are caused by the independent variable(s) in a particular experimental situation (Ary et al., 2002). In addition, external validity refers to the generalizability or representativeness of the findings of the experiment (Cohen, 2000). Therefore an external validity threat limits the generalizability of the treatment outcomes.

Based on Ary et al. (2002) and Campbell and Stanley (1996), Table 2 summarizes the internal and external validity threats that can confound the effect on the dependent variables in an experiment. The design utilizes control group, using random assignment to equalize the comparison groups, which eliminate all the threats to internal validity. Due to thesis, there considerable confidence that any differences between treatment group and control group are due to treatment (Ary et al., 2002). In order to ensure that the change in marital satisfaction is due to treatment not other factors, the researcher takes various steps to control other factors that may influence the result of the study. A reminder is given to the participants to ensure their attendance by sending SMS one day before each session and also to remind participants of the session. These might decrease and minimize attrition of participants in the process of the study.

A briefing session is done at the beginning of the skills training program to ensure that participants commit themselves to the eight weeks of training. Informed consent is obtained from the participants before the actual training started. On top of this, the standardized procedures and activities outlined in the skills training program activity are strictly followed by the researcher. To minimize difference between the three subgroups each of which included 10 couples undergoing treatment and receiving training, the groups are facilitated by the same person and held in the same location.

\subsection{Population and Sampling}

In this study, the population included all couples, referred to the researchers from counseling centers within a space of two months. Their problems were marital difficulty and marital conflict, these cases being referred as cases of marital dissatisfaction. The concept marital dissatisfaction was identified after formal interviews and screening. Purposive sampling with random assignment method was used in the research. The study was carried out with 108 participants. The sample size comprised of 54 males and 54 females. The sample was randomly assigned to treatment and control groups were based on odd and even numbers.

So each group had 27 males and 27 females. Couples, who volunteered to improve their marital relationship, were invited to participate in the program. Enrich Questionnaires was distributed to the couples as pre-test. The researcher assumed that the couples went through at least secondary education in order to understand and answer the questionnaire. Other criteria of participants in the study included a at least age of 18 years who lived together at the time of their participation in the study.

\subsection{Determining the Sample Size}

The determination of sample size is an essential step in the statistical design of the research. It is important because adequate sample size ensures reliable results of the research. There are some statistical parameters, which are effective in the determination of sample size. These consist of effect size index, significant criterion, and statistical inference power. As the parameters are completely interrelated, if the researcher knows one, it is possible to determine the others. There are also some well-known rules for determining each parameter, for instance, when determining power for a study, it can be set at .80 (Cohen, 1988). Another common rule related to significant levels by Cohen (1997) is that, in most cases, alpha .05 value is acceptable. Another common rule related to significant levels by Cohen (1997) is that, in most cases, alpha .05 value is acceptable. However, for any two tailed tests where the alternative hypothesis shows that $\mathrm{Ma} \neq \mathrm{Mb}$, we can conventionally use medium Es, which equal to .5. As already said, with respect to the two mentioned parameters, the sample size can be determined. For this purpose Table 2.4.1 (Cohen, 1988, p. 55) can be referred to, with regard to power and effect size. As the study was two-tailed, the sample size was 26 for each group.

\subsection{Screening and Selection}

\section{Screening}

Screening and selection were done to avoid offering the program to couples, who were severely distressed or functioning poorly. This was because the program was not designed for individuals, with very severe emotional problems those intense marital conflicts. Therefore, screening couples was a three-step process. Before any of the actions above, couples were screened for to ensure they were 18 years and above, and having at least five years of education and lived together at the time of their participation in the study (include criteria). The first screening process was by phone interview was conducted followed by a face-to-face interview. The 
twenty-minute phone interview obtained enough information to rule-out couples, who were clearly inappropriate for the group.

The phone interview identified couples, who were not married, physically aggressive to each other, had experiences of extramarital affairs in their history, separated, had substance abuse histories and were in concurrent couple therapy. Generally, couples having ongoing problems with the above "risk" factors were not suitable for the study. In fact, if they answer in the positive direction for more than three of these risk criteria, they were eliminated from the study (exclude criteria).

In the second part, the follow-up face-to-face meeting was used for screening and rapport building with the couples, before the program started. During the conjoint interview, symptoms of serious destructive interaction patterns or pathology that were not apparent from the phone screening were also assessed. In addition, if a couple showed other risk indicators in the interview, such as the case where only one spouse was interested in the training program, or one of them has a history of an extramarital affair, or a conflicting interaction style, these risk indicators were also assessed.

Following the interview, the MCQ was used to screen couples with severe conflict. Couples, who scored between 80 to 190 scores, were assigned as suitable couples for the total sample of the research. During the interview, the filled-up consent forms and ground rules for group participation were reviewed. At last, eligible candidates were assigned in two groups randomly. One group acted as the experimental group and the second as the wait-list control group.

This study was limited to examining only two types of the PREPARE/ENRICH program's goals, which are as follows:

1) Learning useful communication skills like assertiveness and active listening.

2) Learning Conflict Resolution skills by using the Ten Steps Procedure.

\section{Communication Skills}

In the acquisition of couple communication skills, assertiveness and listening are specifically emphasized because they help to increase the positive cycle of assertiveness, enhance self-confidence and minimise the negative cycle of avoidance and partner dominance, both in the case of the individual and as a couple. It is then up to the counselor to provide the couple meaningful and positive evaluation of their assertiveness and active listening skills and encouragement on how to continue building these important skills (Olson, 2004).

\section{Conflict Resolution}

This section includes discussion on lack of conflict resolution skills, different conflict resolution styles, constructive and destructive approaches to conflict resolution, and finally Ten Steps for Resolving Couple Conflicts. For this purpose, the couple, together with the counselor review the Ten Steps when discussing feedback, focusing on a particular growth area at the onset. The couple would then choose a particular issue which they will work on at home and then discuss at the following session (Olson, 2004).

\subsection{Measurement Instruments}

\section{Marital Conflict Questionnaire (MCQ)}

The Marital Conflict Questionnaire (MCQ) is a 54-item screening questionnaire which measures the husband and wife conflicts and was provided by Dr. B. Sanai et al., (2009) based on his clinical experiences. In 2009, Marital conflict Questionnaire (MCQ) was developed by Sanai, Barati and Boostanipoor for measuring wife and husband conflicts and eight basic of marital conflicts including; decreasing in cooperation, sexual relationship, increasing in excitement reaction, increasing in attracting children's support; individual relationship with relatives, decreasing in family relationship with spouse's relatives or friends, dividing financial affairs and decreasing in affective communication. Counsellors and other clinical experts can use this questionnaire for evaluating husband and wife conflicts. Cronbach Alpha as an analytic tool was conducted for the 270 respondents. The Cronbach's alpha was .96 total items.

\section{Enrich Marital Satisfaction}

Marital satisfaction were evaluated by ENRICH marital satisfaction scale. The Enrich Questionnaire (EQ) is based on the questionnaire which developed by David H, Olson, David G. Fournier and Joan M. Druckman (1989). In this study, marital satisfaction was measured with Enrich Questionnaire (Enriching and Nurturing Relationship Issues, communication and Happiness). The ENRICH Questionnaire is a self-report measure of a couple's marital satisfaction. It is a Questionnaire that measures marital interaction and assesses married couples 
seeking to either enhance their relationship or facilitate the process of marital therapy. This inventory was specifically designed for the assessment of engaged couples. It identified relationship strengths and work areas for each couple. The scale was also constructed in such a way as to promote couples dialogue and to help promote greater relationship enhancement (Olson, Fournier \& Druckman, 1986).

The ENRICH marital inventory was evaluated for internal consistency and test retest reliability. Internal consistency was .86 Cronbach's alpha. Test retest reliability was .86 for 115 individuals over four weeks (Olson, 1998). Many studies have also confirmed the reliability and validity of the scale.

\section{Result and Disscution}

Hypothesis 1: There is a significant difference in the marital satisfaction between pre-test and post-test in the experimental group.

All participants in the experimental group and control group sat for the assessment. The paired sample t-test was performed to assess the significant difference in marital satisfaction between pre-test and post-test of the experimental group, based on achievement.

The results of the paired sample t-test (Table 4) illustrate the pre-test score for the experimental group $(M=37.16$, $S D=7.31)$ while post-test score had the mean value of $(M=41.18, S D=5.91)$. Based on the data above, the mean score for the pre-test experimental group is 37.16 compared to the mean score for the post-test of the experimental group which is 41.18 . Higher mean values in post-test indicated that the couples performed better when compared to the performance at the pre-test experimental stage.

The t-value, degree of freedom, and the two-tail revealed significant difference $(p<.05)$ between the mean scores of the pre-test $(M=37.16, S D=7.31)$ and that of the post-test experimental group $(M=41.18, S D=5.911)$ (score for post-test experimental group $=41.18$, score for pre-test experimental group $=37.16, P<.05$ ) which suggests that communication and conflict resolution training program led to the promotion of marital satisfaction. Thus, the result shows that there was a significant difference in mean value $(t=6.34, p<.05)$ between the pre-test and the post-test score of the experimental group.

Cohen's (1988) criteria can be applied to interpret the effect size value based on the following guidelines: $\leq .49$ is small effect, $.50-.79$ is moderate effect, and $\geq .80$ is large effect. It is obvious that the effect size of $(d=.86)$ obtained is considered to be large. A large effect suggests that the mean difference of the marital satisfaction score for post-test and pre-test in the experimental group is very large.

The results indicate that participating in communication and conflict resolution skills of ENRICH was highly effective in sustaining marital satisfaction. Couple communication and marriage improvement programs as well as results from previous studies on the positive effects of marital satisfaction also support the findings of this study. Most of the previous studies depended on post-test score after group therapy to determine behavioral modification (Yalcin and Karahan, 2007). The present research, which is experimental, differs from previous studies as it examines the relationship between communication skills and marital satisfaction. The main focus of past studies has been on the relationship of communication skills and marital satisfaction (Gottman, 1994; Litzinger and Gordon, 2005; Yalcin and Karahan, 2007). This present study adds to and complements the existing body of research with its examination of the effects of communication skills training as well as conflict resolution among Iranian couples. The finding confirms the assertion that the program is effective in improving marital satisfaction among Iranian couples. This finding is consistent with the first assumption of Satir (1982), who confirmed the notion that the natural movement of all individuals is towards growth and development. Also, this study has been able to gather some empirical evidence that corroborates some of the earlier findings reported in the literature. The result of the study indicates that couples who participated in communication and conflict resolution skills and completed the skills training had significantly higher mean score of marital satisfaction than those who were in the control group. Results indicated that participants who received communication and conflict resolution skills training showed more significant gains from pre-test to post-test. Although, marital communication and marital conflicts have separate impacts on marital satisfaction, however, the combination of good communication and positive conflict resolution aimed at achieving marital satisfaction and good mental health has not been extensively studied. Couples trained in communication and conflict resolution skills are expected to enjoy higher marital satisfaction. Furthermore, couples maybe able to discuss ideas and experiences with one another, thus enhancing their learning experience. As shown in the results, the mean scores of the experimental group were higher after eight weeks of communication and conflict resolution skills training. This established the fact that communication and conflict resolution skills training are important to the improvement of marital satisfaction. 
This study sought to introduce a new program for the prevention of marital distress in line with a previous programme by Olson and Olson (2000) known as the PREPARE/ENRICH program. Specifically, communication and conflict resolution skills help couples to cope or overcome their marital conflicts and improve their marital satisfaction. Consequently, those couples who experienced higher marital problem and conflict may need professional help (communication and conflict resolution skills) to cope with marital problems and marital conflict with the aim of maintaining healthy status. Thus, high marital problem may lead to mental health problems, mental illnesses, marital distress and divorce.

The findings of this study were also supported by couple communication and marriage improvement programs as well as results from previous studies on the positive effect of marital satisfaction. Most of the previous studies depended on post-test score after group therapy to determine behavioural modification (Yalcin and Karahan, 2007). A large percentage of the research on marital communication dwelled on the relationship between communication skills and marital satisfaction (Gottman, 1994; Litzinger and Gordon, 2005; Yalcin and Karahan, 2007; Khoshkam, Ahmadi and Adedi, 2008). Consequently, the result of the study was consistent with earlier studies conducted in other parts of the globe. The finding as a result confirms the assertion that the program was effective in improving marital satisfaction among Iranian couples.

Hypothesis 2: There is significant difference in the marital satisfaction between post-test of experimental group and control group.

After exploratory data analysis, both assumption of normality and equality of variance (based on table of test of normality, skewness, Kurtosis) were met. Therefore, the analysis conducted is deemed appropriate. A two -tailed independent samples t-test was calculated to compare the difference in the mean of the post-test score of the experimental group and post-test score of the control group. Table 5 shows the mean scores of the experimental and control groups. The data shows that the mean score for the control group is 35.64 whereas the experimental group's mean score stands at 41.18 .

As displayed in Table 5, the pos-test score of the experimental group has a mean value of $M=41.18, S D=5.91$, while the pos-test score of the control group has a mean value of $(M=35.64, S D=7.46$. Higher mean value of the post-test in the experimental group illustrates that the couple's marital satisfaction is better in the pos-test of the control group. Therefore, the results show that there was a significant difference in the mean value $(t=4.27$, $p<.05$ ) between the post-test score of the control group and the post-test score of the experimental group in terms of marital satisfaction. This indicated that the former group performed better than the latter group in the post test. The scores of the post-test (at the end of the program) for the experimental group attending communication and conflict resolution skills proves to be higher in total than the scores of the control group who did not attend (post-test experimental group $=41.18$, post-test control group $=35.64, t=4.27, p<.05$ ). This was because the t-statistic obtained (4.27) revealed that the there is significant difference between the experimental group and the control group.

Although there are large bodies of research on the effectiveness of marital education programs in western countries, there is, however, a lack of experimental studies on the effectiveness of such programs in Iran. There has been no report of the positive impact of such programs on health issues, as well. Consequently, the findings serve to bridge the gap particularly in the Iranian context and confirm the effect of marriage enrichment programs on Iranian couples facing marital conflicts. Specifically, communication and conflict resolution skills help couples to cope or overcome their marital conflicts and improve their marital satisfaction. Gottman \& Levenson (1988), and Rogge \& Bradbur (1999), thus maintain the importance of researchers investigating and explaining the major factors related to the breakdown and success of marriages. The majority of the research devoted to explaining the success or failure of marital relationships have pin pointed the significance of effective communication as a critical aspect of marital satisfaction.

The results of this study indicate that communication and conflict resolution skills' training has positive effects on marital satisfaction. Robinson and Blanton (1993), in their study, investigated the strengths of long-lasting marriages and also identified communication as a key factor in such marital relationships. In line with the above study, the findings of the current study reveal that increased communication and more effective communication improved marital satisfaction whereas a lack of communication between spouses led to poor marital satisfaction.

Further support of the findings of this study are also to be found in the work by Sevier, Eldridge, Jones, Doss and Christensen (2008). Their study involved monitoring the relationship between communication and marital satisfaction in the context of traditional and integrative behavioral therapy among couples. Their conclusion was that marital satisfaction improved with improvements in problem solving as well. In addition, another study carried out by Yalcin and Karahan in 2007 on the effects of the couple communication program on marital 
adjustment similarly supported the results of the present study. Yalcin and Karahan reported that the couple communication program had positive effects on marital adjustment levels by improving communication skills, which led to behavioral modifications among couples.

Additionally, these findings were also supported by Khoshkam, Ahmadi and Adedi (2008) study on the effect of communication training on couples' relationship in Isfahan, Iran. Khoshkam et. al., (2008) reported that couple communication training program improved couples' relationship. A significant difference was also found in marital satisfaction with the experimental group scoring higher than the control group. From the other point of view, Boostanipoor (2008) study on different aspects of marital conflicts among dual-career couples presented a functional therapeutic pattern. Boostanipoor reported that communication problems could be improved by communication therapies. The result is in line with communication-based approach of systems-behavioural therapies.

In 2006, Besharat, Tashk and Rezazadeh conducted a study on the role of coping in marital satisfaction in Iran. They explained marital satisfaction according coping styles among a sample of married students from Tehran University. Besharat et. al., (2006) highlighted the benefits to marital satisfaction of effective coping styles. They concluded that problem focused and positive emotional strategies had positive effects on marital satisfaction. On the other hand, according to their study, any negative effects were associated with psychological distress that impacted negatively on marital relationships. It was also found that an emotionally negative coping style led to psychological stress and impacted negatively on the level of marital satisfaction. The finding of the study was also supported by Nazari and Navabinezhad (2007) in their study on the effect of solution-focused counselling on marital satisfaction among career couples in Iran also supported the findings of the study, which demonstrated that solution-focused counselling increased significantly the level of marital satisfaction of couples.

In a survey similar to the current inquiry, Olson and Miller (2007) attempt at integrating "PREPARE/ENRICH and couple communication program". The research paper demonstrated that this led to significantly improve their communication, conflict resolution skills and marital satisfaction. The findings in this section were also supported by Cornelius, Alessi, and Shorey (2007) revealed that communication skills prevented marital distress. Additionally, in line with the above and in agreement with the current study Resnick (2007) indicated that negative communication resulted in low level of satisfaction.

The present research has shown that spousal communication and conflict resolution skills training - made available to couples who experience problems in their marriage-improve communication between spouses. Such skills training also positively impact on the conflict resolution skills of spouses and their marriage congruity. Studies done on communication and conflict resolution skills maintain that the basis of all relationships lies on couple's ability to make meaning through communication. Countless studies have emphasized the importance of communication as the hallmark of successful family relationship (Galvin, Bylund \& Brommel, 2004). Nevertheless, a significant portion of the researches on marital communication have focused on the link between communication skills and marital satisfaction (Westerp, 2002).

There has been intensive study of both positive and negative communication and what has emerged is a general consensus that couples who face distressed relationships are likely those who show signs of constant negative interaction (Johnson \& Bradbury, 1999; Gottman \& Levensohn, 1992; Vanzetti, Notarius, \& Nee Smith, 1992; Christensen \& Shenk, 1991; Gottman \& Krokoff, 1989). In a study by Baucom, Hahlweg, Atkins, Engl, and Thurmaier (2006), in their research focused on the implications of changes in communication styles as a predictor of marital distress and concluded that significant changes in communication styles had greater impact on the prediction of marital distress than small or no changes. This, they also concluded, was regardless of whether the changes were destructive or constructive.

In all, research shows that the use of communication in handling conflict and as a predictor of marital satisfaction or dissatisfaction is emphasized by McNulty and Karney (2004) and Bradbury and Canary (2003). A study performed by Bakhshi, Asadpour and Khodadadizadeh (2007) found that relationship between poor marital quality and mental health provides evidence for the fact that the more intense the depression among husbands and wives, the less their marital satisfaction. Such findings corroborate the first and second hypotheses. The findings of this preset study indicate a difference between the pre- and post-test scores of subjects in the experimental group. Couples in the experimental group scored much higher than the ones in the control group. This supports the results in the literature concerning the crucial relationship between communication and marriage.

Kurdek (2002) and Larson and Holman (1994), noted that couples who possessed communication-related skills like empathy, active listening and conflict resolution were able to have more stable and satisfying marriages. 
Various researches over the years have confirmed the importance of communication as a significant factor in marriage relations and satisfactory levels of marital satisfaction (Butler and Wampler, 1999; Markman et. al., 1993). A study by Litzinger and Gordon (2005) also supports the findings of this study, which explored the relationships between communication, sexual satisfaction, and marital satisfaction, identifying the crucial link between sexual satisfaction and communication in predicting marital satisfaction.

There has been consistent confirmation of a clear relationship between behaviours in communication and patterns of interaction and the state of marriages. Although it has been widely emphasized that skills in communication influence the outcome of marital relationships, it has also been confirmed that these communication skills are not the only influential factor that affects marriages for there are also various aspects of individuals and their marital relationships that serve to change the impact of communication on marital happiness. Additionally, Gordon, Baucom, Epstein, Burnett, and Rankin (1999) have shown how standards and beliefs that are focused on relationships could conceivably affect the relationship between communication and happiness in marriage.

The findings of this study suggest that communication and conflict resolution training program lead to the promotion of better communication among Iranian couples. From the results, it can be seen that marital communication and conflict resolution can have a positive impact on couple communication in order to find solutions to any conflicts that may occur. This finding is supported by Gottman (1994) who indicated that poor communication skills preceded the onset of marital problems. Many studies have found an association between communication and relationship satisfaction in other type of research designs (Christensen \& Shenk, 1991; Bradbury \& Karney, 1993).

\section{Conclusion}

Based the result, the first hypothesis was accepted. Consequently, there was significant difference between the means score marital satisfaction of the pre-test and post-test experimental group. Results reveal that the mean of post-test was higher than the mean of the pre-test (in experimental group). Therefore, the finding indicated that the program was effective in improving marital satisfaction among Iranian couples. The mean score also showed that the experimental groups were generally more satisfied in their marriage than the control group. Therefore, there are significant mean differences among these two groups at level of significance .05 with regard to marital satisfaction. Based on the result, the second hypothesis was accepted in the current research. Consequently, there was significant difference between the mean of marital satisfaction of the post-test in the experimental and control groups. Results reveal that the mean of post-test was higher than the mean of pre-test. Therefore, the finding indicated that the program was effective in improving marital satisfaction among Iranian couples.

\section{References}

Amato, P. R., Johnson, A. B., \& Rogers, S. J. (2003). Continuity and change in marital quality between 1980 and 2000. Journal of Marriage and Family, 65 (1), 1- 21.

Analysis. Clinical Psychology Review, 13, 15-27.

Ary, R., Jacobs, L. C., \& Razavieh, A. (2002). Introduction to research in education, (6 $6^{\text {th }}$ ed.). Orlanda: Harcourt Brace College Publishers.

Babbie, E. (2004). The practice of social research. $\left(10^{\text {th }}\right.$ ed.). Belmont, CA: Wadsworth/ Thomson learning.

Bakhshi, H., Asadpour, M., \& Khodadadizadeh, A. (2007). Correlation between Marital Satisfaction and Depression among Couples in Rafsanjan, Iran. The Journal of Qazvin University of Medical Sciences \& Health Services, 2(11), 37-43.

Besharat, M. A., Tashk, A., \& Rezazadeh, M. R. (2006). Explaining the Role of Coping in Marital Satisfaction and Mental Health. Journal of the Iranian Psychology Association, 1(1), 48-56.

Boostan, A. Hashemian, K. Shafiabadi, A., \& Delavar, A. (2008). A Comparative Study of Effectiveness Between Group Couple Therapy with Teaching the "Redecision Therapy" and the "Narrative Therapy" Approaches on increasing Marital Satisfaction of College-student Marriages in Iran. Journal of Counseling Rrsearch and Developments, 6(24), 79-102.

Boostan, A., Hashemian, K., Shafiabadi, A., \& Delavar, A. (2008). A Comparative Study of Effectiveness Between Group Couple Therapy with Teaching the "Redecision Therapy" and the " Narrative Therapy" Approaches on Increasing Marital Satisfaction of College-student Marriages in Iran. Journal of Counseling Rrsearch and Developments, 6(24), 79-102.

Boostanipoor, A. R. (2008). The Effects of Systemic-Behavioral Couple Therapy on Marital Conflicts of the 
Dual-Career Couples. Unpublished Thesis Tarbiat moallem university of Tehran.

Bradbury, T. N., \& Karney, B. R. (1993). Longitudinal study of marital interaction and dysfunction: Review and

Butler, M. H., \& Wampler, K. S. (1999). A meta-analytic update on research on the Couple Communication Program. American Journal of Family Therapy, 27, 223.

Campbell, D. T., \& Stanley, J. C. (1966). Experimental and quasi-experimental design for research. Boston: Houghton Mifflin Company.

Christensen, A., \& Shenk, J. L. (1991). Communication, conflict, and psychological distance in nondistressed, clinic, and divorcing couples. Journal of Consulting and Clinical Psychology, 59, 458-463.

Cohen, J. (1988). Statistical Power Analysis for the Behavioral Sciences. New Jersey: Lawrence Erlbaum.

Cohen, J. (1997). Statistical power analysis for the behavioral sciences (2 ${ }^{\text {nd }}$ ed.). Hillsdale, NJ: Erlbaum.

Danesh, E., \& Hydarian, M. (2006). The Relationship between Mutual Interest and Respect Among Couples and Their Marital Satisfaction in Qom City,Iran. Journal of Counseling Research \& Developments, 18, 59-76.

DiLillo, D. (2001). Interpersonal functioning among women reporting a history of childhood sexual abuse: Empirical findings and methodological issues. Clinical Psychology Review, 21, 553-576.

Dimitrov, D. M., \& Rumrill, P. D. (2003). Pretest-posttest designs and measurement of change. Work, 20, $159-165$.

Gattis, K. S., Berns, S., Simpson, L. E., \& Christensen, A. (2004). Birds of a feather or strange birds? Ties among personality dimension, similarity, and marital quality. Journal of Family Psychology, 18, 564-574.

Gordon, K. C., Baucom, N., Epstein, D. H., Burnett, C. K., \& Rankin, L. A. (1999). The interaction between marital standards and communications patterns: How does it contribute to marital adjustment? Journal of Family and Marital Therapy, 25 (2), 211- 223.

Gordon, K. C., Baucom, N., Epstein, D. H., Burnett, C. K., \& Rankin, L. A. (1999). The interaction between marital standards and communications patterns: How does it contribute to marital adjustment? Journal of Family and Marital Therapy, 25 (2), 211- 223.

Gottman, J. (1994). What Predicts Divorce? The Relationship Between Marital Process and Marital Outcomes, Lawrence Erlbaum, New Jersey.

Gottman, J. M. (1994). Why marriages succeed or fail. New York: Simon and Schuster.

Gottman, J. M., \& Driver, J. L. (2004). Daily marital interactions and positive affect during marital conflict among newlywed couples. Family Process, 43, (3), 30-43.

Gottman, J. M., \& Levenson, R. W. (1988). The Social Psychophysiology of Marriage. In Perspectives on Marital Interaction, ed. P. Noller and M. A. Fitzpatrick. Philadelphia: Multilingual Masters.

Gottman, J. M., \& Levenson, R. W. (1988). The Social Psychophysiology of Marriage. In Perspectives on Marital Interaction, ed. P. Noller and M. A. Fitzpatrick. Philadelphia: Multilingual Masters.

Greef, A. P., \& De Bruyne, T. (2000). Conflict management style and marital satisfaction. Journal of Sex and Marital Therapy, 26, 321-334.

Halford, W. K., \& Moore, E. (2002). Relationship education and the prevention of couple relationship problems. In A. S. Gurman (Ed.), Clinical handbook of couple therapy (3rd ed., pp. 400-419). NewYork: Guilford

Halford, W. K., \& Simons, M. (2005). Couple Relationship Education in Australia. Family Process, 44 (2), $147-159$.

Harper, J. M., Schaalje, B. G., \& Sandberg, J. G. (2000). Daily hassles, intimacy, and marital quality in later life marriages. The American Journal of Family Therapy, 28, 1-18.

Kaplan, M., \& J. E. Maddux (2002). Goals and marital satisfaction: Perceived support for personal goals and collective efficacy for collective goals. J. Soc. Clin. Psychol, 21, 157-164.

Khojastehmehr, R., \& Takrimi, A. (2009). Identification of divorce factors of women. Journal of Applied Sciences, 9 (20), 3758-3763.

Khoshkan, S., Ahmadi, S. A., \& Abedi, M. R. (2008). The Effect of Communication Training on Couples' Relationship in Isfahan, Iran. Journal of Counseling Research and Developments, 6(24), 123-136. 
Kurdek, L. A. (2002). Predicting the timing of separation and marital satisfaction: An eight-year prospective longitudinal study. Journal of Marriage and Family, 64, 163-179.

Larson, J. H., \& Holman, T. B. (1994). Predictors of marital quality and stability. Family Relations, 43, 228-237.

Litzinger, S., \& Gordon, K. C. (2005). Exploring relationships among communication, sexual satisfaction, and marital satisfaction. Journal of Sex \& Marital Therapy, 31(5), 409-424.

Markman, H. J., Renick, M. J., Floyd, F. J., Stanley, S. M., \& Clements, M. (1993). Preventing marital distress through communication and conflict management training: A 4- and 5-year follow-up. Journal of Consulting and Clinical Psychology, 61, 70-77.

McNulty, J. K., \& Karney, B. R. (2004). "Should I Expect the Best or Brace for the Worst?" The Role of Positive Expectations in the Early Years of Marriage. Journal of personality and Social Psychology, 86, 729-743.

Nazari, A. M., \& Navabinezhad, S. (2007). Study of the effect of Solution-Focused Counseling on Marital Satisfaction of Dual-career Couples in Iran. Journal of Counseling Rrsearch and Developments, 5(20), 53-80.

Nazari, A. M., \& Soleimanian, A. A. (2008). Comparason between Dual Career Couple and Single Career Couples on Marital Satisfaction in Iran. Journal of Counseling Rrsearch and Developments, 6(24), 103-122.

Olson D. H., \& Olson A. K. (2000). Prepare-Enrich Program: version. In: Berger R, Hannah M, editors. Preventive approaches in couples therapy. Lillington (NC): Edwards Brothers; 1999. p. 197-202.

Olson, D. H. (2004). PREPARE/ENRICH Counselor's Manual. Minneapolis/Life Innovations Inc.

Olson, D. H., \& Miller, S. (2007). Integrating PREPARE/ENRICH \& Couple Communication program: A Longitudinal Follow-Up [Online] Available: $\mathrm{http}: / /$ www.prepare/enrich.Com/pe_main_site_content/pdf/research/pe_and_cpl communication.pdf.

Resnick, E. M. (2007). The Relations among Differing Forms of Psychopathology Symptoms, Couple Communication, and Relationship Satisfaction. Published master dissertation, University of Maryland, College Park.

Rogge, R. D., Bradbury, T. N., Hahiweg, K., Engi, J., \& Thurmaier, F. (2006). Predicting marital distress and dissolution: Refining the two-factor hypothesis. Journal of Family Psychology, 20(1), 156-159.

Samani, S. (2008). The Important Factors of in Marital Conflict Between Married Students in Shiraz University of Iran. Journal of Family Research, 3 (3), 657-668.

Samani, S. (2008). The Important Factors of in Marital Conflict Between Married Students in Shiraz University of Iran. Journal of Family Research, 3 (3), 657-668.

Sanai, B., Alaghband, S., Falahati, S., \& Hooman, A. (2009). Family and Marriage Scales. Tehran, Iran. Besat Publishing.

Sayers, S. L., Kohn, C. S., \& Heavey, C. (1998). Prevention of marital dysfunction: Behavioral approaches and beyond. Clinical Psychology Review, 18, 713-744.

Schneewind, K., Klaus, A., \& Gerhard, A. (2002). Relationship personality, conflict resolution, and marital satisfaction in the first five years of marriage. Family Relations, 51(1), 63-72.

Sepahvand, T., Guilani, B., \& Zamani, R. (2007). Relationship between Attributional Styles with Stressful Life Events and General Health. Journal of Psychological Research, 9, 33-46.

Sevier, M., Eldridge, K., Jones, J., Doss, B. D., \& Christensen, A. (2008). Observed changes in communication during traditional and integrative behavioral couple therapy. Behavior Therapy, 39, 137-150.

Vanzetti, N. A., Notarius, C. I., \& Nee Smith, D. (1992). Specific and generalized expectancies in marital iteraction. Journal of Family Psychology, 6, 171- 183.

Waite, L., \& Gallagher, M. (2000). The case for marriage. New York: Doubleday.

Westerop, K. R. (2002). Building Healthy Couple Relationship: Does Communication Skills, Gender, Hope, And Family Type Make A Difference? Published Master dissertation, University of Trinity Western.

Yalcin, B. M., \& Karahan, T. F. (2007). Effects of a Couple Communication Program on Marital Adjustment. JABFM, 20 (1), 36-44.

Zargar, F., \& Doost, H. T. N. (2008). Divorce incidence factors in falavarjan township. Journal of Family Research, 3, 737-749. 
Table 1. Randomized subjects, pre-test-post-tests control group design

\begin{tabular}{|c|c|c|c|}
\hline Group & Pre-test & Treatment & 8th week Post-test \\
\hline RE & O1 & $\mathrm{X}$ & O2 \\
\hline RC & O3 & - & O4 \\
\hline
\end{tabular}

The Os in table 1 signify the observation in pre and post test (Babbie, 2004).

Table 2. Internal and external validity

\begin{tabular}{|c|c|c|}
\hline Sources of Invalidity & Definition & Measure to control possible threats \\
\hline 1. History: & $\begin{array}{l}\text { Specific unanticipated events } \\
\text { occurring between measurements } \\
1 \text { and 2. In addition to the } \\
\text { experimental variable. The } \\
\text { event/s may affect the subject's } \\
\text { responses. }\end{array}$ & $\begin{array}{l}\text { Random assignment } \\
\text { Using control group } \\
\text { To the knowledge of the researcher } \\
\text { no study has been conducted in Iran } \\
\text { in this light. } \\
\text { The duration of the study was not } \\
\text { more than two months. }\end{array}$ \\
\hline 2.Maturation & $\begin{array}{l}\text { Is defined as the growth and } \\
\text { maturation of the subjects over } \\
\text { time across the experiment (Ary } \\
\text { et al., 2002, p. 304). }\end{array}$ & $\begin{array}{l}\text { The whole period of the study lasted } \\
\text { for eight weeks that can result in } \\
\text { participants' maturation through } \\
\text { channels other than the treatment } \\
\text { received from the trainer. } \\
\text { Therefore, the respondents were } \\
\text { screened to control for this } \\
\text { intervening variable. } \\
\text { Using control group and } \\
\text { Randomization }\end{array}$ \\
\hline 3.Testing & $\begin{array}{l}\text { Is defined as the effect of taking a } \\
\text { second test. }\end{array}$ & $\begin{array}{l}\text { A pre-test given to the participants to } \\
\text { ascertain the homogeneity between } \\
\text { the research groups. In addition, the } \\
\text { pre-test design's most important } \\
\text { feature, provides away to deal with } \\
\text { this treat. } \\
\text { The pre-test enabled the researcher to } \\
\text { check the equivalence of the groups. } \\
\text { Thus, if there are no significant } \\
\text { difference on the pretest, we can } \\
\text { selections could be eliminated as a } \\
\text { threat to interval validity of the study. }\end{array}$ \\
\hline 4.Statistical Regression & $\begin{array}{l}\text { Is defined as the selection of } \\
\text { groups on the basis of their } \\
\text { extreme scores. Usually low or } \\
\text { high performance will cause the } \\
\text { subjects, on the average, to score } \\
\text { closer to the mean on subsequent } \\
\text { testing. }\end{array}$ & $\begin{array}{l}\text { The selection of couples was not } \\
\text { based on extreme scores. } \\
\text { Furthermore, EDA measure was } \\
\text { checked to ensure the normality of } \\
\text { the sample. Also, both experimental } \\
\text { and control groups took the same } \\
\text { pre-test and post-test, and the study } \\
\text { occurred the same time. }\end{array}$ \\
\hline
\end{tabular}


Continued (Table 2)

\begin{tabular}{|c|c|c|}
\hline 5.Experimental Mortality & $\begin{array}{l}\text { Is defined as the loss of } \\
\text { respondents from the comparison } \\
\text { group. }\end{array}$ & $\begin{array}{l}\text { In order to minimize the possibility of } \\
\text { attrition, each participant was offered } \\
\text { an incentive. The incentive was } \\
\text { presented three potential } \\
\text { opportunities: 1. Participants and } \\
\text { their spouses could participate in, and } \\
\text { learn about, the communication and } \\
\text { conflict resolution skills training at } \\
\text { no financial cost. } \\
2 \text {. Participants who attended } \\
\text { communication and conflict } \\
\text { resolution skills' training received a } \\
\text { certificate of completion } \\
3 \text {. In addition, the research was done } \\
\text { with an extensive effort to maintain } \\
\text { all participants through the schedules } \\
\text { and meeting locations. In this } \\
\text { research, the motivation was same for } \\
\text { both the treatment and the control } \\
\text { groups. Also, researchers added } 6 \\
\text { subjects for each group. }\end{array}$ \\
\hline 6.Selection & $\begin{array}{l}\text { Is defined as the biases resulting } \\
\text { from the differential selection of } \\
\text { respondents for the comparison } \\
\text { groups. }\end{array}$ & $\begin{array}{l}\text { Controlled by having couples with } \\
\text { similar backgrounds as possible. The } \\
\text { couples should have at least } \\
\text { secondary education, in order to } \\
\text { understand the questionnaire and } \\
\text { answer it. In addition, individuals } \\
\text { will be } 18 \text { years of age or older. }\end{array}$ \\
\hline $\begin{array}{l}\text { 7.Instrumentation } \\
\text { Instrument Decay }\end{array}$ & $\begin{array}{l}\text { Is defined as an instrument with } \\
\text { long scoring procedure which } \\
\text { may result in fatigue. Changes in } \\
\text { the observers or scorers used may } \\
\text { produce changes in the } \\
\text { measurement. }\end{array}$ & $\begin{array}{l}\text { ENRICH questionnaire questionnaire } \\
\text { has high reliability and validity. }\end{array}$ \\
\hline $\begin{array}{l}\text { 8.Interaction of selection } \\
\text { and other threats }\end{array}$ & $\begin{array}{l}\text { Interaction of different extraneous } \\
\text { variables that may be mistaken } \\
\text { for the effect of the experimental } \\
\text { variable }\end{array}$ & $\begin{array}{l}\text { This is controlled as much as possible } \\
\text { by ensuring that everything but the } \\
\text { treatments was identical. So, a single } \\
\text { trainer was used for both groups to } \\
\text { ensure uniformity. }\end{array}$ \\
\hline $\begin{array}{l}\text { 9. Multiple-treatment } \\
\text { interference }\end{array}$ & $\begin{array}{l}\text { Likely to occur whenever } \\
\text { multiple treatments are applied to } \\
\text { the same responds, because the } \\
\text { effect of prior treatment was not } \\
\text { usually erasable. }\end{array}$ & $\begin{array}{l}\text { Screening and selection was } \\
\text { performed to avoid offering the } \\
\text { program to couples, who are in } \\
\text { concurrent couple's therapy. Hence, } \\
\text { they will be eliminated from the } \\
\text { study. This was the first study which } \\
\text { was done in Bandar Abbas. So, there } \\
\text { is no probability of multiple } \\
\text { treatments at the same time }\end{array}$ \\
\hline
\end{tabular}


Table 3. Sample size

\begin{tabular}{|l|l|l|l|}
\hline \multirow{2}{*}{ Group } & \multicolumn{2}{|c|}{ Couple } & \multirow{2}{*}{ Total } \\
\cline { 2 - 3 } & Male & Female & \\
\hline Experimental & 30 & 30 & 60 \\
\hline Control & 30 & 30 & 60 \\
\hline Total & 60 & 60 & 120 \\
\hline
\end{tabular}

Table 4. Pre-test and post-test marital satisfaction scores for experimental group

\begin{tabular}{|l|l|l|l|l|l|l|}
\hline Test & Group & $\boldsymbol{n}$ & Mean & SD & $\boldsymbol{t}$ & $p$ \\
\hline Pre-test & \multirow{2}{*}{ Experimental } & 54 & 37.16 & 7.31 & 6.34 & .000 \\
Post-test & & 54 & 41.18 & 5.91 & & \\
\hline
\end{tabular}

$* p<.05$

Table 5. Post-test of marital satisfaction scores for experimental group and control group

\begin{tabular}{|l|l|l|l|l|l|l|}
\hline Test & Group & $\boldsymbol{n}$ & mean & SD & $\boldsymbol{t}$ & $\boldsymbol{p}$ \\
\hline Post-test & Experimental & 54 & 41.18 & 5.91 & 4.27 & .000 \\
\hline Post-test & Control & 54 & 35.64 & 7.46 & & \\
\hline
\end{tabular}

$* p<.05$ 